Short Circuit Current

Contribution for Different Wind Turbine Generator Types

\section{Preprint}

E. Muljadi and V. Gevorgian

National Renewable Energy Laboratory

N. Samaan

Pacific Northwest National Laboratory

J. Li

EnerNex Corporation

S. Pasupulati

Oak Creek Energy Systems Inc.

To be presented at the IEEE Power and Energy Society 2010 General Meeting

Minneapolis, Minnesota

July 25-29, 2010
Conference Paper NREL/CP-550-47193

March 2010 


\section{NOTICE}

The submitted manuscript has been offered by an employee of the Alliance for Sustainable Energy, LLC (ASE), a contractor of the US Government under Contract No. DE-AC36-08-GO28308. Accordingly, the US Government and ASE retain a nonexclusive royalty-free license to publish or reproduce the published form of this contribution, or allow others to do so, for US Government purposes.

This report was prepared as an account of work sponsored by an agency of the United States government. Neither the United States government nor any agency thereof, nor any of their employees, makes any warranty, express or implied, or assumes any legal liability or responsibility for the accuracy, completeness, or usefulness of any information, apparatus, product, or process disclosed, or represents that its use would not infringe privately owned rights. Reference herein to any specific commercial product, process, or service by trade name, trademark, manufacturer, or otherwise does not necessarily constitute or imply its endorsement, recommendation, or favoring by the United States government or any agency thereof. The views and opinions of authors expressed herein do not necessarily state or reflect those of the United States government or any agency thereof.

Available electronically at http://www.osti.gov/bridge

Available for a processing fee to U.S. Department of Energy and its contractors, in paper, from:

U.S. Department of Energy

Office of Scientific and Technical Information

P.O. Box 62

Oak Ridge, TN 37831-0062

phone: 865.576 .8401

fax: 865.576 .5728

email: mailto:reports@adonis.osti.gov

Available for sale to the public, in paper, from:

U.S. Department of Commerce

National Technical Information Service

5285 Port Royal Road

Springfield, VA 22161

phone: 800.553.6847

fax: 703.605.6900

email: orders@ntis.fedworld.gov

online ordering: http://www.ntis.gov/ordering.htm 


\title{
Short Circuit Current Contribution for Different Wind Turbine Generator
}

\author{
Eduard Muljadi, Senior Member, IEEE, Nader Samaan, Member, IEEE, Vahan Gevorgian, Member, IEEE, \\ Jun Li, Member, IEEE, Subbaiah Pasupulati, Member, IEEE
}

\begin{abstract}
An important aspect of wind power plant (WPP) impact studies is to evaluate the short circuit (SC) current contribution of the plant into the transmission network under different fault conditions. This task can be challenging to protection engineers due to the topology differences between different types of wind turbine generators (WTGs) and the conventional generating units.

This paper presents simulation results for SC current contribution for different types of WTGs obtained through transient analysis using generic WTG models. The obtained waveforms are analyzed to explain the behavior, such as peak values and rate of decay, of the WTG. The effect of fault types and location, and the effect of the control algorithms of power converters on SC current contribution are also investigated.

We show that the response of the WPP to faults will vary based on the type of the installed WTGs. While in Type 1 and Type 2 WTGs, SC current will be determined by the physical characteristics of the induction generator, the contribution of Type 3 and Type 4 WTG will be mostly characterized by the power converter's control algorithms, which are usually considered proprietary information by the wind turbine manufacturers.
\end{abstract}

Index Terms - Fault contribution, induction generator, protection, short circuit, wind power plant, wind turbine.

\section{INTRODUCTION}

$\mathrm{R}$ ECENTLY, the energy and environmental crises have become one of the biggest issues around the world. In response to energy needs and environmental concerns, renewable technologies are considered the future energy technologies of choice [1], [2]. Renewable energy is harvested from nature, and it is clean and free. However, it is widely accepted that renewable energy is not the panacea that comes without challenges. With the federal government's aggressive goal of achieving $20 \%$ wind energy penetration by 2030 , it is necessary to understand the challenges that must be overcome when using renewable energy.

One aspect of planning a wind power plant is the calculation of short circuit (SC) current contribution from a wind power plant (WPP). With the different types of wind turbine

This work was supported financially by the Department of Energy and the California Energy Commission.

Eduard Muljadi and Vahan Gevorgian are with the National Renewable Energy Laboratory, Golden, CO 80401 USA (e-mail: eduard.muljadi@nrel.gov, vahan.gevorgian@nrel.gov).

Nader Samaan is with the Pacific Northwest National Laboratory, Richland, WA 99352 USA (e-mail: nader.samaan@pnl.gov).

Jun Li is with EnerNex Corporation, Knoxville, TN 37932 USA (e-mail: jun@enernex.com).

Subbaiah Pasupulati is with Oak Creek Energy Systems Inc, Mojave, CA 93501 USA (e-mail: subbaiah@oakcreekenergy.com). generators (WTGs) available from different turbine manufacturers, the task of computing SC current is no longer a simple task as in calculating SC current for a synchronous generator in a conventional power plant [3], [4]. In a synchronous generator, the magnetizing flux is controlled by the field current exciting the field winding, thus, the electromagnetic force (EMF) driving the fault currents is available during the fault. In contrast, in an induction generator the magnetizing flux is depleted during the fault and the fault currents are not sustainable for a long duration.

In the years to come, there will be more and more WPPs connected to the grid. With the goal of $20 \%$ wind penetration by 2030, the WPPs operation should be very well planned. The power system switchgear and power system protection for WPPs should be carefully designed to be compatible with the operation of conventional synchronous generators connected to the same grid. This paper attempts to illustrate the behavior of SC current contributions for different types of WTGs.

The organization of this paper is as follows: In section II, the SC characteristics of different WTGs types will be presented. In section III, the aggregated SC current contribution of a WPP will be presented. In section IV, the conclusion will summarize the paper.

\section{EXPlanAtion OF THE NATURE OF THE SHORT CirCUIT CURRENT OF DiFFERENT Wind TURBINE GENERATORS}

In the early development of wind energy, the applications were mostly non-grid applications (water pumping, battery charging, etc.). Eventually, application of wind turbine generators included grid-connected wind turbines, where the owner of wind turbine sells electricity to consumers via a power system grid. A utility sized wind turbine is larger than non-grid wind turbine applications. In the early days, the turbines were sized from $10 \mathrm{~kW}-100 \mathrm{~kW}$. Nowadays, wind turbines are sized above $1000 \mathrm{~kW}(1 \mathrm{MW})$.

\section{A. Type 1 - Squirrel Cage Induction Generator}

The first generation of utility sized wind turbine generator is a fixed speed turbine with a squirrel-cage induction generator (SCIG). The induction generator generates electricity when it is driven above synchronous speed. The difference between the synchronous speed and the operating speed of the induction generator is measured by its slip (in per unit or in percents). A negative slip indicates that the wind turbine operates in generating mode. Normal operating slips for an induction generator are between $0 \%$ and $-1 \%$.

The induction generator torque increases (almost) linearly with the speed. A typical real power versus slip characteristics 
profile is shown in Fig. 1, where the WTG reaches its rated $\left(\omega_{\text {rated }}\right)$ output at $105 \%$ synchronous speed $\left(\omega_{\mathrm{s}}\right)$ or slip= 0.005 p.u. or $-0.5 \%$. The real power output varies in similar fashion within the narrow rated slip range. By its nature, an induction generator consumes reactive power both in the motoring and generating regions. The reactive power increases significantly as the output power increases.

The connection diagram of a Type 1 WTG connected to the grid via a pad-mounted transformer equipped with switched capacitor banks to compensate the induction generator at unity power factor is shown in Fig. 2.

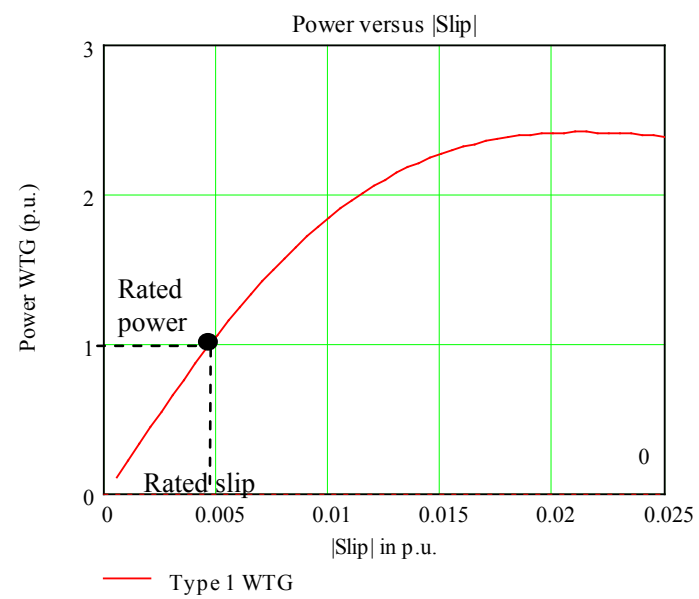

Fig. 1. The relation between real power and slip of a Type 1 WTG.

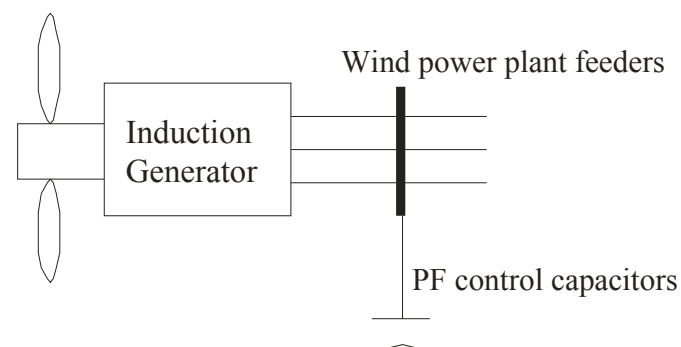

Fig. 2. Type 1 wind turbine generator connected to the grid.

The waveforms of SC currents of Type 1 WTGs for different fault types are shown in Fig. 3-the generator is shorted at its terminals. Notice that Type 1 WTGs are able to contribute significant fault current. Depending on the time of the SC, the contribution during the initial cycle of the fault (asymmetrical current) can be as high as six times the rated current or more. As the fault persists, the contribution decreases in magnitude. More simulation results and analysis for a Type 1 WTG are given in [5].
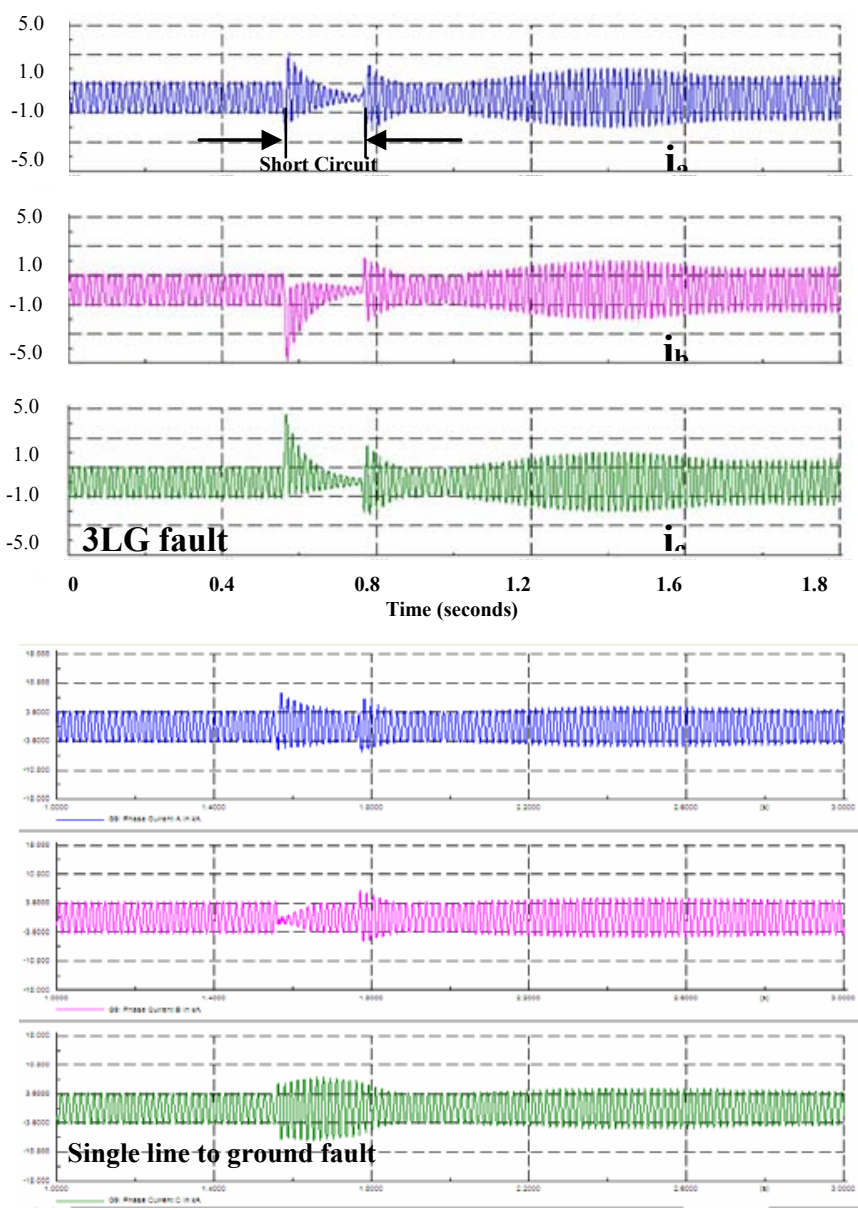

Fig. 3. SC currents of Type 1 WTGs for different fault types.

\section{B. Type 2 - Wound-Rotor Induction Generator with Variable External Rotor Resistance}

Another type of utility size WTG is the variable-slip wind turbine with a wound-rotor induction generator (WRIG). The three-phase rotor winding is connected to a power electronic component and three-phase external resistance. The external rotor-resistance controller (ERRC) is a very fast controller that allows the effective rotor resistance to vary, thus the torque speed characteristic of the WRIG can be shaped accordingly. The connection of a Type 2 WTG is illustrated in Fig. 4.

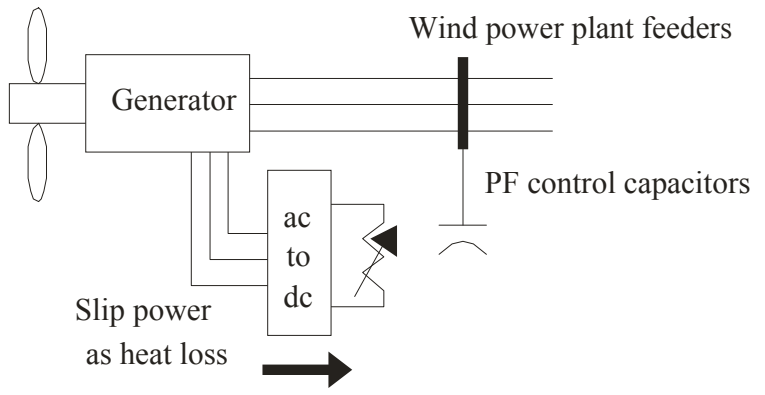

Fig. 4. A Type 2 wind turbine generator connected to the grid.

The equivalent circuit of a Type 2 WTG is shown in Fig. 5. The power speed characteristic can be seen in Fig. 6 . 


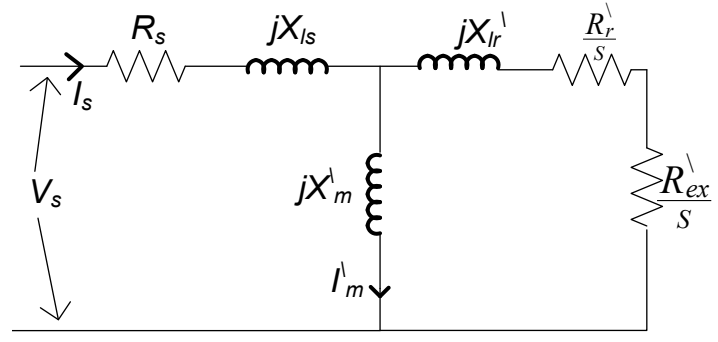

Fig. 5. An equivalent circuit for a Type 2 WTG.

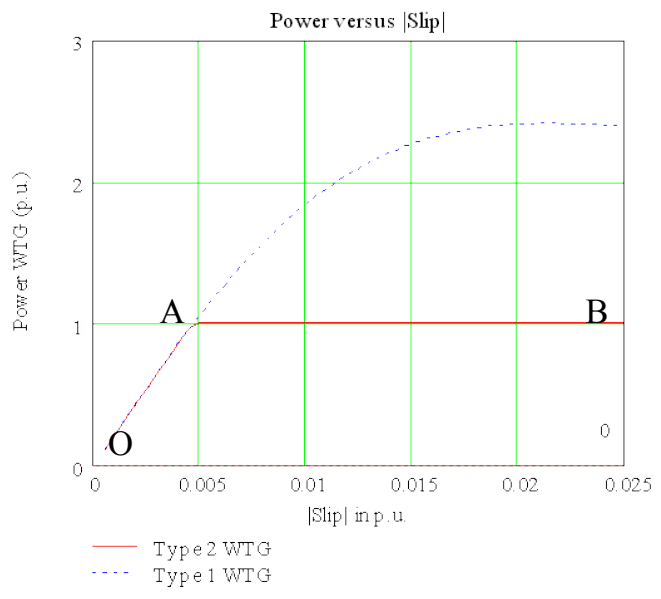

Fig. 6 . The relation between real power and slip of a Type 2 WTG.

A Type 2 WTG is controlled in a similar way as the Type 1 WTG. In the low to medium wind speeds, the pitch angle is set to the optimum value (e.g., 0 deg) and the ERRC is controlled to keep the external resistance to be minimum (e.g., $0 \mathrm{ohm}$ ). Thus, in this wind speed range, the operation of a Type 2 WTG is the same as for a Type1 WTG. When the output power of the wind turbine reaches its rated value (at rated slip), the fast EERC is adjusted to keep the output power constant. If the pitch angle of the blades is kept constant at zero degree, the rotor speed and thus, the slip will vary with the wind speed. However, operation at higher slips generates a lot of loss because of the rotor resistance, thus, the heat loss can be excessive. On the other hand, if the pitch angle of the blades is controlled to keep the rotor speeds within a small deviation from the rated slip, the losses in the rotor resistance can be minimized. As shown in Fig. 6, the path OA is operated at optimum pitch angle $\left(0^{\circ}\right)$, and the path $\mathrm{AB}$ is operated with an adjustable external rotor resistance to keep the rated power constant, while the pitch angle is controlled to minimize the slip and it attempts to operate the turbine as close to point $\mathrm{A}$ as possible.

From the equivalent circuit shown in Fig. 5, we can derive the following equation to freeze the equivalent circuit as the slip varies.

$\mathrm{R}_{\mathrm{r}}{ }^{\prime} / \mathrm{S}_{\text {rated }}=\left(\mathrm{R}_{\mathrm{r}}{ }^{\prime}+\mathrm{R}_{\mathrm{ex}}{ }^{\prime}\right) / \mathrm{Slip}$

$\mathrm{R}_{\mathrm{ex}}{ }^{\prime}=\operatorname{Slip} \mathrm{R}_{\mathrm{r}}{ }^{\prime} / \mathrm{S}_{\text {rated }}-\mathrm{R}_{\mathrm{r}}{ }^{\prime}$

$\mathrm{R}_{\mathrm{ex}}{ }^{\prime}=\mathrm{R}_{\mathrm{r}}{ }^{\prime}\left(\mathrm{Slip} / \mathrm{S}_{\text {rated }}-1\right)$

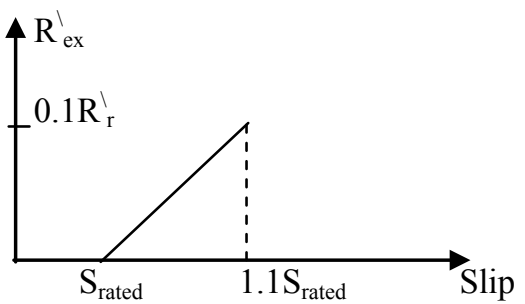

Fig. 7. The variation of $R_{\text {ex }}^{\backslash}$ to maintain the output power constant at $P_{\text {rated }}$ from slip $=\mathrm{S}_{\text {rated }}$ to slip $=1.1 \mathrm{~S}_{\text {rated }}$.

Normal operating slip for an induction generator is between $0 \%$ and $-1 \%$; however, in a Type 2 wind turbine, the slip is allowed to vary within $-10 \%$ slip although the pitch angle is controlled to minimize the operating slip (to be as close to rated slip, thus minimizing the heat loss in the rotor resistance).

The SC contribution of a Type 2 is similar to a Type 1 . When the external rotor resistance is shorted, (i.e., operation below rated slip), the SC current is similar to the squirrel-cage induction generator. Operation in higher slip than the rated slip requires that the external rotor resistance is adjusted higher than zero. Operating at higher rotor resistance produces a lower SC current than the SC current of a squirrel-cage induction generator (Type $1 \mathrm{WTG}$ ). The SC current for three different sizes of total rotor resistance values is shown in Fig. 8. In this case, the total resistance is scaled as the multiples of the original rotor resistance. The highest rotor resistance generates the lowest SC current and the highest damping coefficient. The blue line is the predicted SC current for zero external rotor resistance. The peak value of the $\mathrm{SC}$ current is computed using the (4) given in [6].

$\mathrm{I}_{\text {sc_peak }}=\mathrm{V}_{\text {ph_peak }} /\left(\mathrm{X}_{\mathrm{ls}}+\mathrm{X}_{\mathrm{lr}}, / \mathrm{X}_{\mathrm{m}}\right)$

Where the symbol // indicates the parallel reactance of $\mathrm{X}_{\mathrm{lr}}{ }^{\prime}$ and $\mathrm{X}_{\mathrm{m}}$ '. Note that the computed value (blue-line) predicts only the peak value of the sinusoidal (non-dc) component of the waveforms; the dc offset of the fault current depends on the current flow at the beginning of the fault.

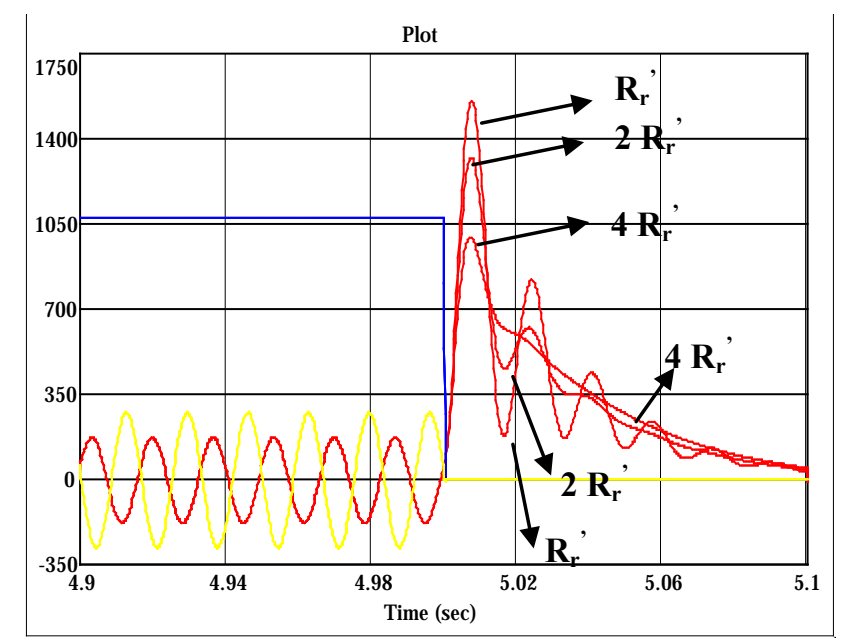

Fig. 8. SC current (3LG) of a Type 2 WTG for different values of rotor resistance.

The rotor resistance can be controlled as shown in Fig. 7. 


\section{Type 3-Doubly Fed Induction Generator}

A Type 3 WTG is implemented by a doubly fed induction generator (DFIG) as shown in Fig. 9 -it is a variable speed WTG. The rotor speed is allowed to vary between 0.3 slip to 0.3 slip, thus, the power converter can be sized to about $30 \%$ of rated power (partial rating). The wind turbine is operated at optimum $\mathrm{C}_{\mathrm{p}}$ below rated wind speed, and it is operated at $\mathrm{P}_{\text {rated }}$ above rated wind speeds. Thus, maximum energy yield is accomplished for low to medium wind speeds. Above rated wind speeds, the aerodynamic power is controlled by pitch to limit rotor speed and to minimize mechanical loads.

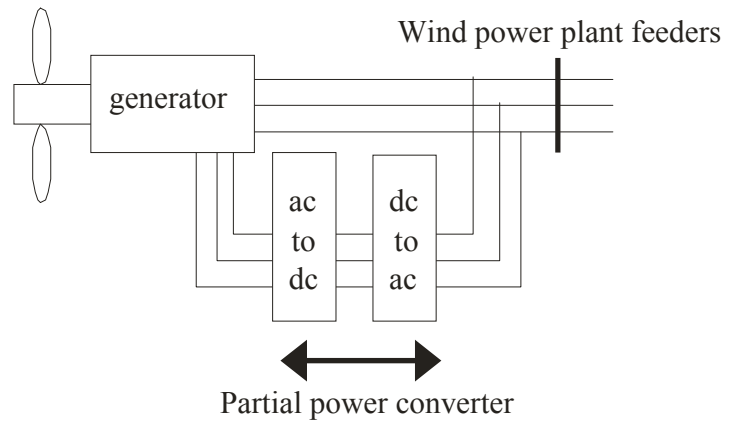

Fig. 9. A Type 3 WTG connected to the grid.

With the use of power converter, the real and reactive power can be controlled independently and instantaneously within design limits. Generally, the real power control capability is used to maximize $\mathrm{Cp}$ below rated speed and to limit output power above rated wind speeds. The reactive control capability is used to control the reactive power, or power factor, or voltage.

The use of the power converter allows the rotor speed to rotate at a different speed with respect to the synchronous speed, thus the rotor speed is not synchronized to the air-gap flux. With this capability, the generator is capable of not participating in power system oscillation that may result in the post transient condition. Flexible grid integration, good power quality, and voltage ride through can be realized in this type of WTG.

An example of typical SC current of Type 3 WTG for different fault types is given in Fig. 10. The SC current contribution for three-phase fault is shown to have the shortest decay time with the peak current around 3 per unit. The line-to-lineto-ground (LLG) gives about the same peak as the three-phase faults, but the decay time is longer. The single line-to-ground fault produces the lowest peak current- about 2 per unit - and it also decays longer than the three-phase fault. From Fig. 10, it is shown that the remaining normal voltage connected to the terminal of the generator contributing to keeping the air gap flux relatively high enough, although unbalanced, to keep the SC current feeds the fault in an extended time, while in a three-phase fault case, the voltage collapse depleted the air gap flux and the SC current decreased to zero in a short time.

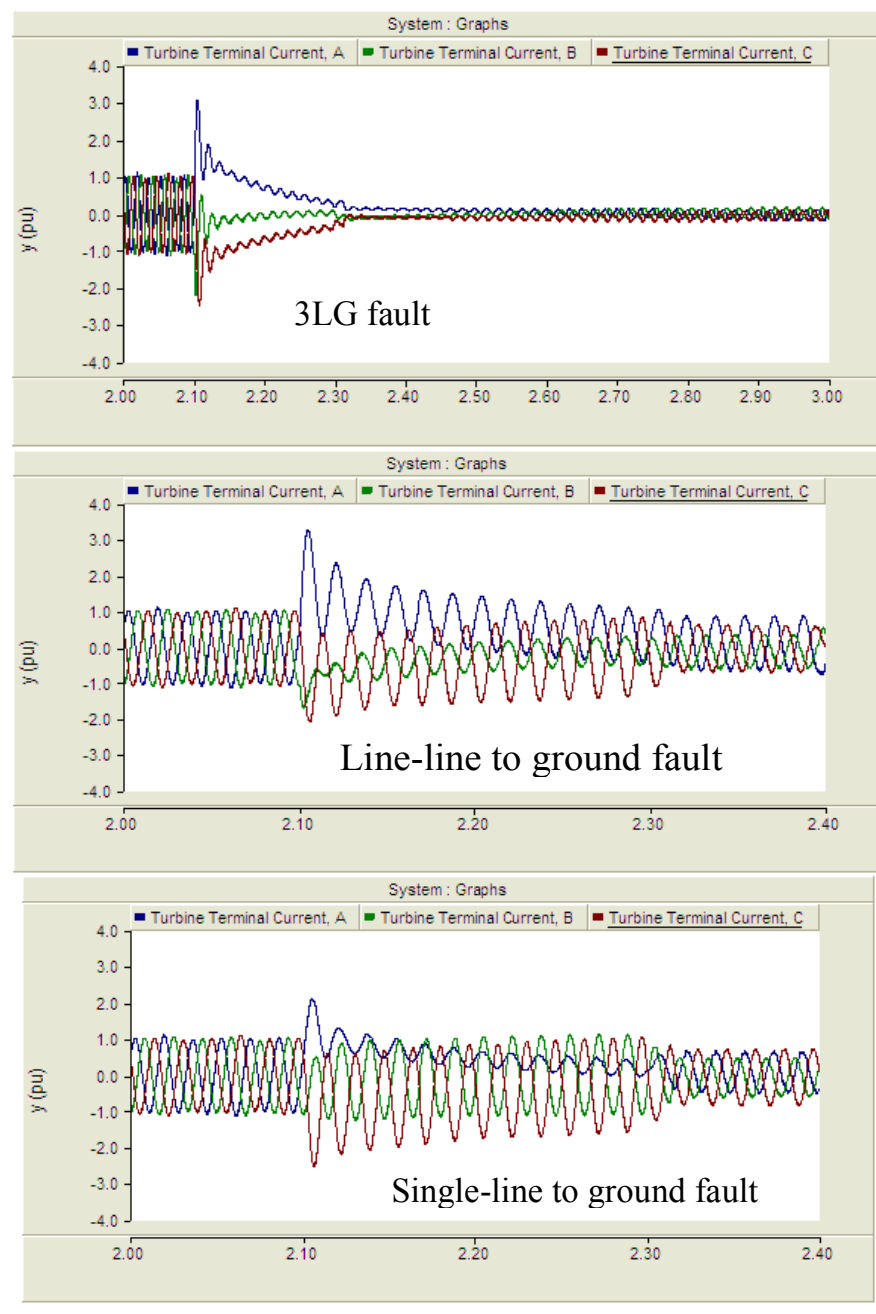

Fig. 10. SC current of a Type 3 WTG for different fault types.

\section{Type 4-Full-Converter Wind Turbine Generator}

A Type 4 WTG is the fourth generation of WTGs, and its depiction is shown in Fig. 11. This is a variable-speed wind turbine generator implemented with full power conversion. Recent advances and lower cost of power electronics make it feasible to build variable-speed wind turbines with power converters with the same rating as the turbines.

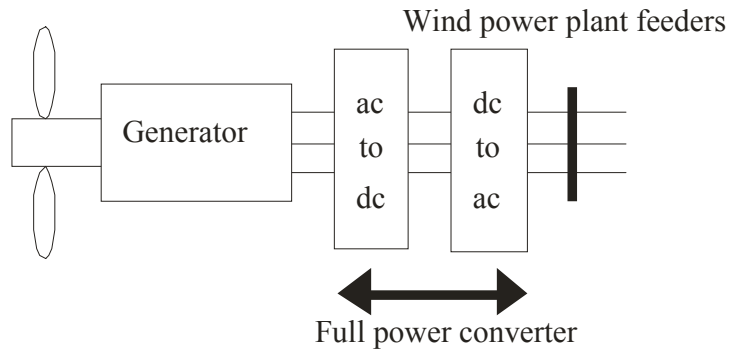

Fig. 11. A Type 4 wind turbine connected to the grid.

The control algorithm is similar to a Type 3 WTG. The wind turbine is operated at optimum $\mathrm{C}_{\mathrm{p}}$ below rated wind speed, and it is operated at $\mathrm{P}_{\text {rated }}$ above rated wind speeds. Thus, maximum energy yield is accomplished for low to medium wind speeds. Above rated wind speeds, the aerodynamic 
power is controlled by pitch to limit rotor speed and to minimize mechanical loads.

With the use of a power converter, the real and reactive power can be controlled independently and instantaneously within design limits. Generally, the real power control capability is used to maximize $\mathrm{Cp}$ below rated speed and set the output power at $\mathrm{P}_{\text {rated }}$ above rated wind speeds. The reactive control capability is used to control the reactive power, or power factor, or voltage.

The full power conversion allows separation between the WTG and the grid, thus, the mechanical dynamic can be buffered from entering the grid and the transient dynamic on the grid can be buffered from entering the wind turbine dynamic. Thus, while the grid is at $60 \mathrm{~Hz}$, the stator winding of the generator may operate at variable frequencies. The temporary imbalance between aerodynamic power and generated power during a transient is handled by the pitch control, dynamic brake, and power converter control.

Like a Type 3 WTG, a Type 4 WTG has flexible grid integration, good power quality, and, voltage ride-through can be easily realized in this type of wind turbine. Figure 11 shows the relationship between the reactive power and the real power. Note that the current limit of the power converter needs to be respected due to the use of power electronics switches (i.e., IGBTs) shown as dash-dot lines in Fig. 12.

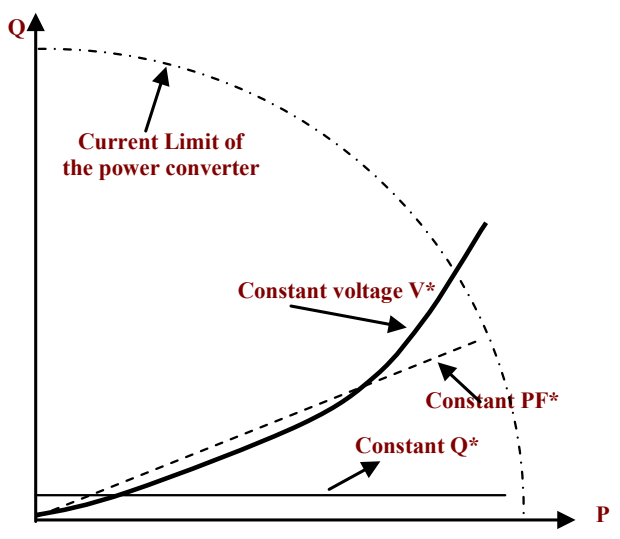

Fig. 12. Commanded reactive power versus real power for different control objectives.

An example of a typical SC current for a Type 4 WTG is given in Fig. 13. The SC current contribution for a three-phase fault is limited to its rated current or a little above its rated current. It is common to design a power converter for a Type 4 wind turbine with an overload capability of $10 \%$ above rated. Note that in any fault condition, the generator stays connected to the power converter and is isolated from the faulted lines on the grid. Thus, although there is a fault on the grid, the generator operates in normal mode. However, keep in mind that with a fault on the grid, the output power delivered to the grid is less than rated power. Although the currents can be made to balance, due to reduced voltage and/or unbalanced voltage, only a reduced output power can be delivered. Therefore, the wind turbine must be controlled to reduce the output accordingly (pitch control and converter control). Any difference in the power converter (i.e., between output power to the grid and input power from the generator) will rise or drop the DC bus voltage. This control algorithm has been used in the industry and it is well understood. Note that in the power converter, the output current to the grid can be balanced and symmetrical regardless of the type of fault.

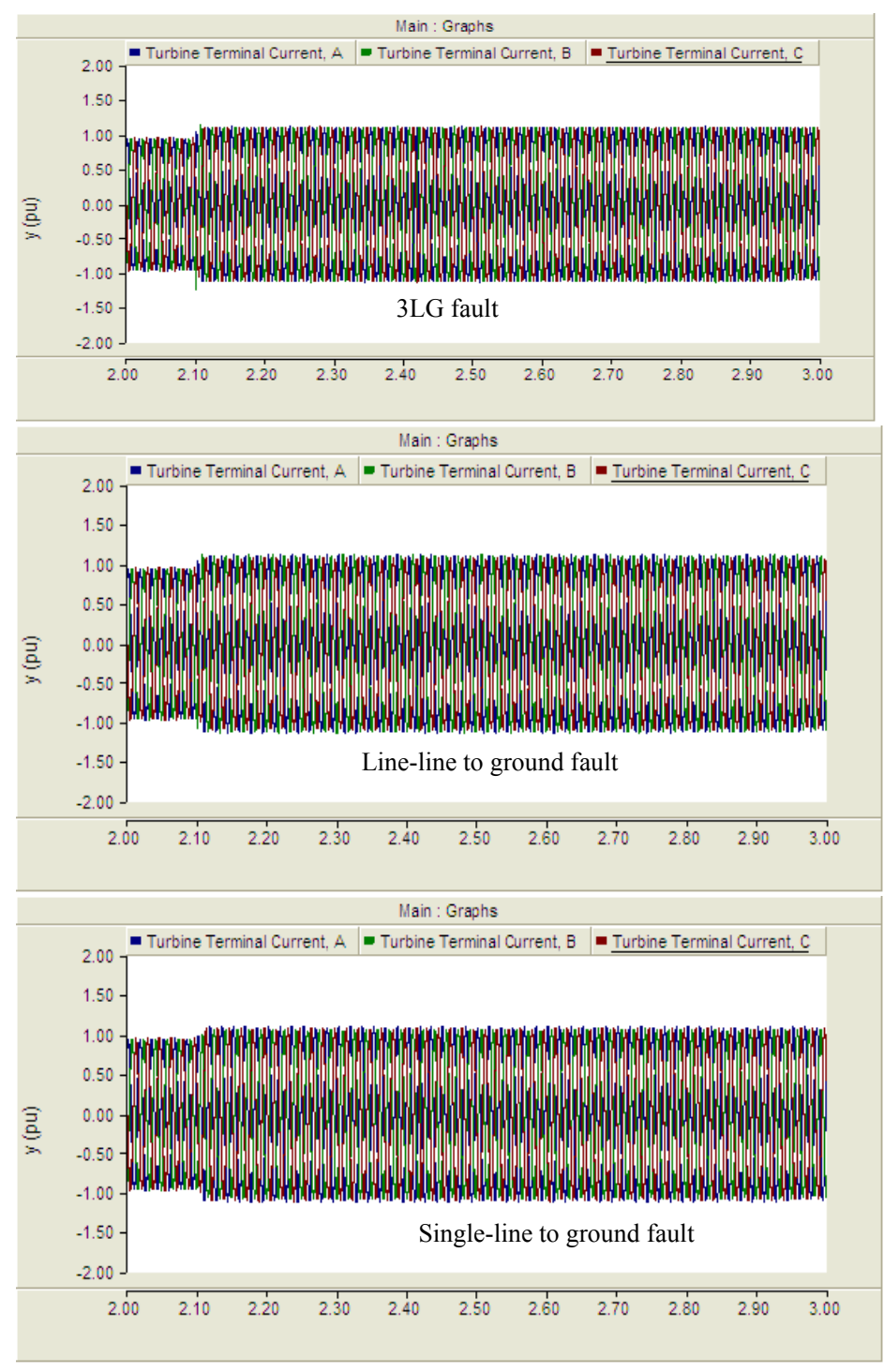

Fig. 13. SC currents of a Type 4 WTG for different fault types.

\section{Aggregated Short Circuit Contribution OF Wind POWER PLANT}

In section II, the SC currents are based on the SC at the terminals of the generator. This calculation is valuable especially for power system planners or wind turbine manufacturers to design system protection of the turbines under SC conditions.

In this section, the WPP scenario is considered. A WPP consists of many (hundreds) of wind turbines. Currently, available WTG sizes are between $1 \mathrm{MW}$ and $5 \mathrm{MW}$. The prime mover of the wind turbine generator is wind, and it is free, natural, and pollution-free. The controllability of the wind power plant is typically curtailment (spilling the wind). 
A WPP depends on the wind variability, and dispatch capability is based on wind forecasting, and it is influenced more by nature (wind) than human factors, with the goal set on maximizing energy production (i.e., unscheduled operation). The WPP is located in a high-wind resource region, and it may be far from the load center. As described in section II, there are four different types of generators commonly used (fixed speed, variable slip, variable speed, and full converter). For Type 3 and Type 4, the wind turbine is variable speed with a fluxoriented controller (FOC) via a power converter. The rotor does not have to rotate synchronously with the rotating flux as in a synchronous generator. Thus, mechanical oscillation of the rotor does not have to be translated into electrical oscillation and vice versa.

\section{A. Conventional power plant versus wind power plant}

A conventional power plant consists of a single or several large (e.g., $100 \mathrm{MW}$ ) generators. The prime mover of the generator can be steam, gas, or a combustion engine. The generator is controllable and it is adjustable up to a maximum limit and down to minimum limit. The power output is dispatched according to the load forecast, influenced by human operation based on optimum operation (i.e., scheduled operation). It is usually located relatively close to the load center. The generator used is a synchronous generator. The rotational speed is fixed speed - no slip; and the flux is controlled via exciter winding. The magnetic flux and the rotor rotate synchronously.

Because of a WPP covers a very large area, there are power output diversities found in a WPP. Each turbine in a power plant will be located at different electrical distances from the substation (diversity in line impedance). Each turbine may be driven by different instantaneous wind speeds. Thus, the operating condition of each turbine may be different from each other.

\section{B. SCt current at the turbine level}

The generator at each turbine should be protected individually and independently because of the diversity of the wind power plant. In practice, this is an advantage of a wind power plant compared to a conventional wind power plant. During a disturbance, the electrical characteristic at each terminal of the turbine is different from the other, and only the most affected turbines will be disconnected from the grid. For general faults (distance faults at the transmission), only $5 \%-15 \%$ of the turbines are disconnected from the grid [7]. Thus, the loss of generation is not as severe as in a power plant with large generators.

At the turbine level, the wind turbine generator generates a low voltage $(480 \mathrm{~V}-690 \mathrm{~V})$. For the type 1 and type 2 generators, it is compensated by switched bank capacitors to generate at a unity power factor. For the type 3 and type 4 generators, it is operated to generate a constant voltage at a designated bus, or it may be operated at constant power factor or constant reactive power. The generator is connected to a pad-mounted transformer to step up the voltage to $34.5 \mathrm{kV}$.

\section{Short circuit current at the collector system}

The collector system consists of miles of line feeders connecting the high side of the pad-mounted transformer to the substation. Usually, the wind turbines are divided into groups of turbines connected in a daisy chain fashion using underground cables. It is then connected to the substation by either underground cables or overhead lines at $34.5 \mathrm{kV}$. Since it is not practical to model hundreds of turbines in a power flow calculation or in a dynamic simulation, it is common to find the equivalent of the turbines as either single equivalent turbine representation or multiple turbine representation [8],[9].

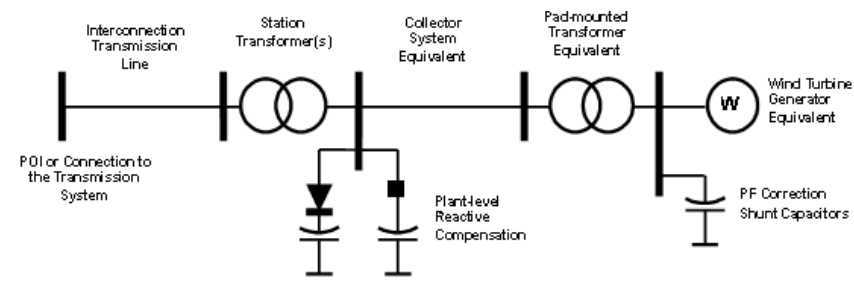

Fig. 14. A typical single-line diagram of WPP.

\section{SC current at the point of interconnection (POI)}

The POI is the node where the utility meets the wind power plant. At this node, meters are installed to monitor the WPP operation (under normal or disturbance conditions, for technical reasons, or for a revenue calculation). This node is usually the high side of the substation transformer, where the voltage is stepped up from $34.5 \mathrm{kV}$ to higher voltages $(230 \mathrm{kV}$ or 500 $\mathrm{kV}$ ).

A typical single turbine representation of a WPP is shown in Fig. 13 as given in [10]. By considering a single turbine representation, all the WTGs in the WPP are assumed to be operating at the same operating condition, thus, a study of the worst case scenario is obtained.

The traces of stator currents, voltages at different nodes, output power and generator speed for a three-phase fault at Node 2 (i.e., high side of the substation transformer) are shown in Fig. 15.

Note that the fault current contribution is smaller than the case with the fault at the terminal of the generator discussed in Section II. This is a result of sufficient impedances between the generator terminals and the fault (i.e., the impedances of the pad mounted transformer, the collector systems, the substation transformer). The terminal voltage of the generator is non zero because there is sufficient voltage drop due to the fault current through the line and the impedance between the fault, the generator terminals, the capacitor compensation at the turbine, and the line capacitance within the collector systems. The output power of the generator decays very rapidly as both the fault currents and the voltage at the terminals die out quickly as the fault progresses. 


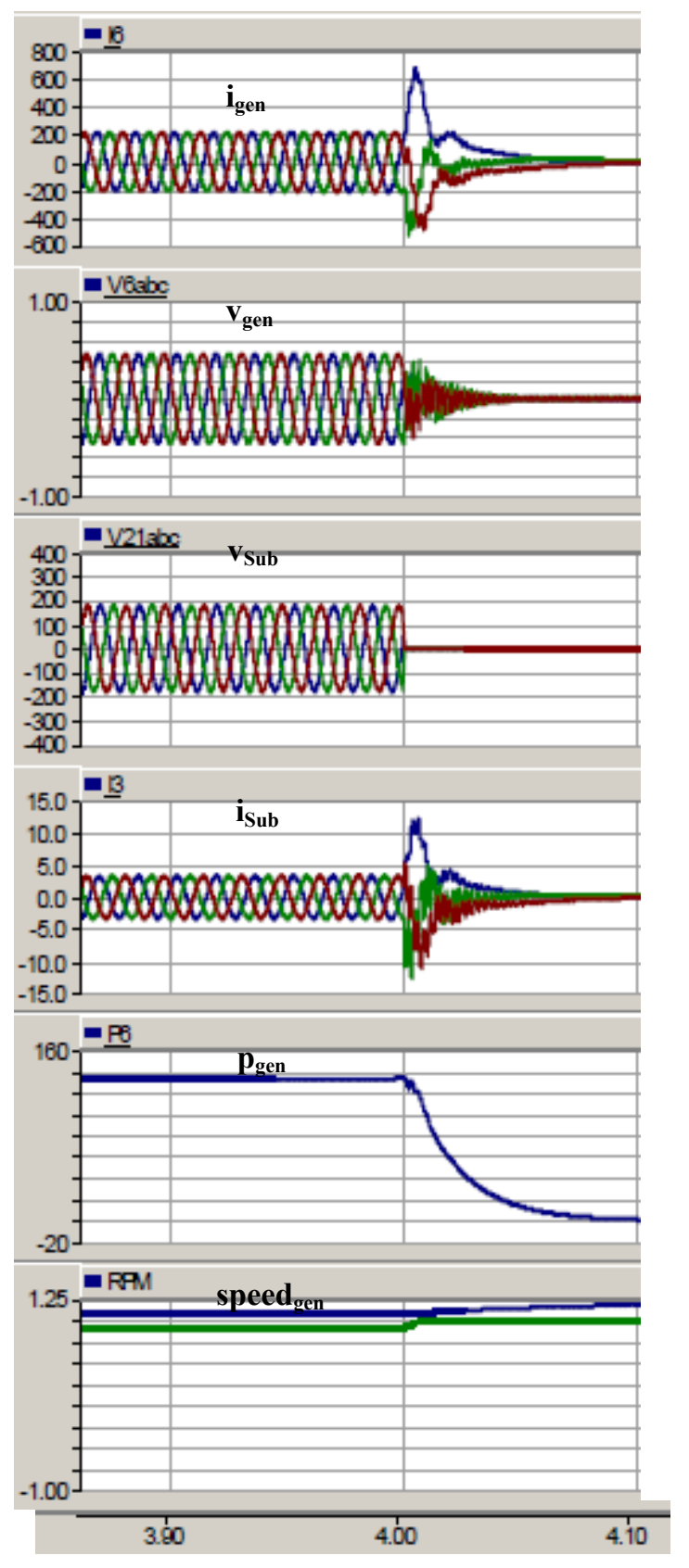

Fig. 15. Traces of currents, voltages, power, and rotor speeds for a Type 2 WTG under three-phase fault at the high side of substation transformer.

The traces for a two-phase to ground fault and a single line to ground fault for a Type 2 WTG is shown in Fig. 16. For both cases, the faults occur at bus 2 (high side of substation transformer). Note that the remaining phases (non-fault phases) contribute to the sustenance of the stator voltage and it helps to sustain the fault current longer than the case for a three-phase fault.

Similar plots can be derived for Type 1, Type 3 , and Type 4 WTGs.

For a Type 4 WTG, the fault current into the POI will be symmetrical because the power converter has the capability to control the current directly. A current-regulated PWM is commonly used to control the output of the power converter.
Thus, although the voltages on the grid may be an unbalance voltage due to the faults, the line current waveforms can be made balanced output by the power converter control.

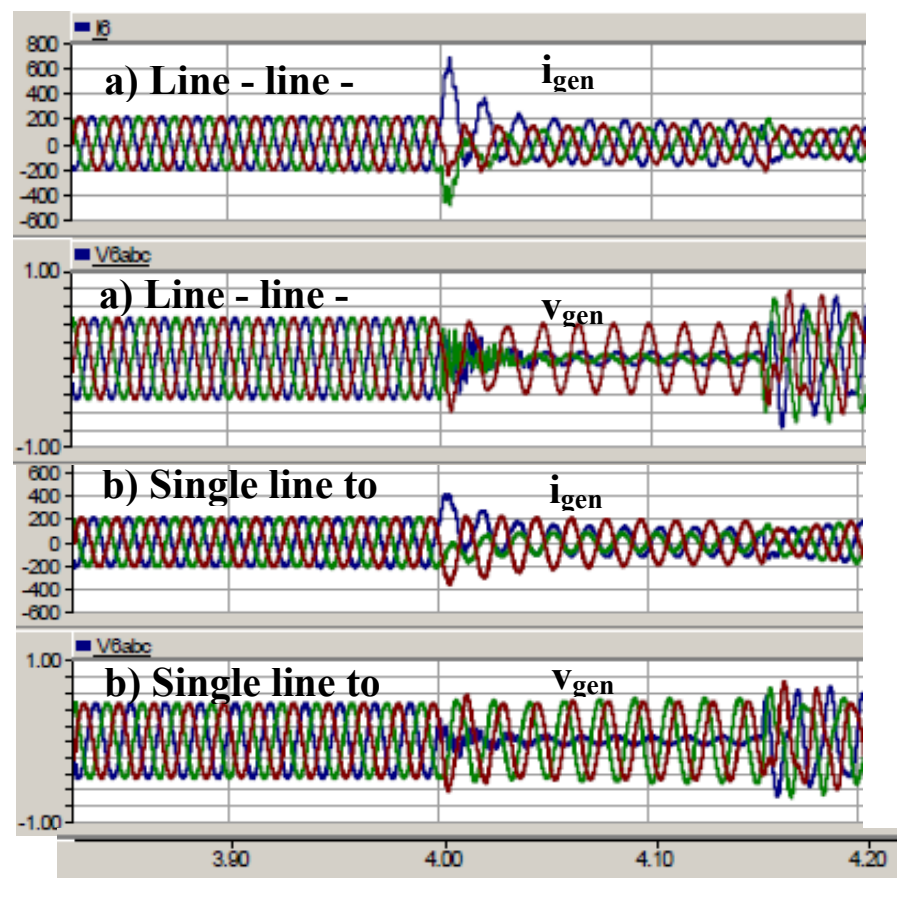

Fig. 16. Generator fault currents and terminal voltages for a fault at bus 2 (high side of substation transformer) for two different faults a) Line-line to ground b) Single line to ground

\section{CONCLUSIONS}

In this paper, the $\mathrm{SC}$ current contributions of different wind turbine generator for faults at the terminal of the generator are explored. For the Types 1, 2, and 3, as expected, the largest $\mathrm{SC}$ current is for the three-phase fault. The duration of the fault is the shortest because the air gap flux collapses without the support of sufficient line voltages. Although this type of fault is the least likely to occur, however, planners use this fault to calculate the circuit breakers duty and other switch gear devices. The single line to ground is the most likely to occur in the power grid. The terminal voltage and currents are sustained longer because the line voltages, except from one phase, are able to sustain air gap flux. Although the SC current contribution from this type of fault is the lowest among the three different faults considered, planners should use this type of fault to determine the minimum fault current setting for protection.

Type 1 and Type 2 WTGs have very similar behavior. The fact that external rotor resistance is used in a Type 2 WTG, the fault contribution for Type 2 WTG may be lower from a Type 1 WTG because the impact of additional rotor resistance reduces the fault current.

For a Type 3 WTG, although there is a power converter at the rotor side, the controllability of this power converter is significantly compromised during a fault event, especially when the fault occurs in the vicinity of the generator (i.e., generator terminals). For a far-away fault in the transmission 
line, the remaining terminal voltage may be sufficient to allow an active control of fault current by the power converter, however, for a near fault event, the crow-bar switch is used to control the DC bus (via dumping resistor), thus avoiding the DC bus voltage from an over voltage condition. With a SC rotor winding, the maximum current condition can be as high as squirrel-cage induction generator (i.e., Type 1 wind turbine).

For a Type 4 wind turbine, the generator and the grid is separated by a power converter. The power converter is limited by its current carrying capability of the power semiconductor used. Thus, the SC current contribution from a Type 4 wind turbine is limited to $110 \%$ of rated current (assuming temporary overload current is designed to be $110 \%$ rated).

\section{ACKNOWLEDGMENT}

The authors wish to thank Dr. Surya Santoso and Mohit Singh of the University of Texas, Austin, for the development of PSCAD models for Type 1 and Type 2 wind turbines used in this paper.

\section{REFERENCES}

[1] U.S. Department of Energy - Energy Efficiency and Renewable Energy, " $20 \%$ Wind Energy by 2030 - Increasing Wind Energy's Contribution to U.S. Electricity Supply,” May, 2008.

[2] J. Charles Smith, Michael R. Milligan, Edgar A. DeMeo and Brian Parsons, "Utility wind Integration and operating impact state of the art," IEEE Trans. Power Systems, vol. 22, pp. 900-908, Aug. 2007.

[3] Short-circuit currents in three-phase a.c. systems-Part 0: Calculation of currents, IEC Standard 60909-0, July 2001.

[4] IEEE Application Guide for AC High-Voltage Circuit Breakers Rated on a Symmetrical Current Basis, IEEE Standard C37.10-2000, Sept. 2000.

[5] Nader Samaan, Robert Zavadil, J. Charles Smith and Jose Conto, "Modeling of Wind Power Plants for Short Circuit Analysis in the Transmission Network," in Proc. of IEEE/PES Transmission and Distribution Conference, Chicago, USA, April 2008.

[6] H. Wayne Beaty, "Handbook of Electric Power Calculations," McGraw Hill, Third Edition, 2001.

[7] E. Muljadi, Z. Mills, A. Ellis, R. Foster, "Fault Analysis at a Wind Power Plant for a One Year of Observation", presented at the IEEE Power Engineering Society, General Meeting, Pittsburgh, PA, July 20-24, 2008.

[8] E. Muljadi, S. Pasupulati, A. Ellis, D. Kosterev, "Method of Equivalencing for a Large Wind Power Plant with Multiple Turbine Representation", presented at the IEEE Power Engineering Society, General Meeting, Pittsburgh, PA, July 20-24, 2008

[9] E. Muljadi, C. P. Butterfield, A. Ellis, J. Mechenbier, J. Hochheimer, R. Young, N. Miller, R. Delmerico, R. Zavadil, and J. C. Smith, "Equivalencing the collector system of a large wind power plant," in Proc. 2006 IEEE Power Engineering Society General Meeting.

[10] "WECC Wind Power Plant Power Flow Modeling Guide" prepared by WECC Wind Generator Modeling Group, May 2008.

\section{BIOGRAPHIES}

Eduard Muljadi (M'92-SM'94) received his Ph. D. (in Electrical Engineering) from the University of Wisconsin, Madison. From 1988 to 1992, he taught at California State University, Fresno, CA. In June 1992, he joined the National Renewable Energy Laboratory in Golden, Colorado. His current research interests are in the fields of electric machines, power electronics, and power systems in general with emphasis on renewable energy applications. $\mathrm{He}$ is member of Eta Kappa Nu, Sigma Xi and a Senior Member of IEEE. He is involved in the activities of the IEEE Industry Application Society (IAS), Power Electronics Society, and Power Engineering Society (PES). He is currently a member of Industrial Drives Committee, Electric Machines Committee, and Industrial Power Converter Committee of the IAS, and a member of Working Group on Renewable Technologies and Dynamic Performance Wind Generation Task Force of the PES. He holds two patents in power conversion for renewable energy.
Nader Samaan (S'00, M'04) received his Ph.D. degree in electrical engineering from Texas A\&M University, USA in 2004. He is currently a senior power systems engineer at PNNL, Richland, WA, USA. Prior to that, he was a power systems engineer at EnerNex Corp. for four years. He was a visiting assistant professor at the department of electrical and computer engineering, Kansas State University during the academic year 2004-05.

His research interests include wind integration studies, power system reliability, harmonics and transient analysis for wind power plants, wind turbine dynamics molding, distributed generation, artificial intelligence and intelligent optimization techniques application to power systems.

Dr. Samaan is a registered professional engineer in the state of Ohio, a member of the IEEE Power Engineering Society and a member of CIGRE.

Vahan Gevorgian (S'01- M'05- SM'08) graduated from the Yerevan Polytechnic Institute (Armenia) in 1986. During his studies he concentrated on electrical machines. His thesis research dealt with doubly-fed induction generators for stand-alone power

Systems. He obtained his Ph.D. degree in Electrical Engineering Dept. from the State Engineering University of Armenia in 1993. His dissertation was devoted to a modeling of electrical transients in large wind turbine generators.

Dr. Gevorgian is currently working at the National Wind Technology Center (NWTC) of National Renewable Energy Laboratory (NREL) in Golden, Colorado, USA, as a research engineer. His current interests include modeling and testing of various applications of small wind turbine based power systems.

Jun Li ( $\left.\mathrm{S}^{\prime} 01, \mathrm{M}^{\prime} 05\right)$ is working at EnerNex Corp. as a power systems engineer, currently conducting simulation and analytical studies of power systems, such as wind generator dynamic modeling, load flow analysis, stability, and short circuit analysis. He has developed wind turbine models using several power system simulation packages such as PSLF and PSCAD. He has a B. Eng. and M. Eng. in Electric Power from Xi'an Jiaotong University, Xi'an, China, and a Ph.D. in Electrical Engineering from Texas A\&M University, College Station, TX. He had worked for four years in Shaanxi Electric Power Research Institute, Xi'an, China as a Power Systems Engineer.

Subbaiah Pasupulati (M’05) graduated from University of Texas, Arlington with an M.S. in Electrical Engineering in 2003. From 2003 to 2005, he was with Energy Unlimited Inc., a Wind Power Plant in Palm Spring, California where he was responsible to oversee the operations of the plant. He joined Oak Creek Energy System Inc. (OCES) in 2006. He is currently the Power System Engineer at OCES, he involved in design and development of $2.5 \mathrm{GW}$ plus wind power plants in the Tehachapi area. He participated in California Southern Regional Transmission Plan 2006 conducted by California Independent System Operator which came up with Tehachapi's Renewable Transmission Plan. He is a member of the IEEE. He is an active member of WECC's Technical Studies Subcommittee \& Wind Generator Modeling Group. 


\section{REPORT DOCUMENTATION PAGE}

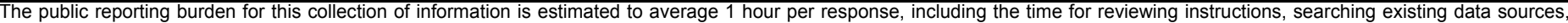

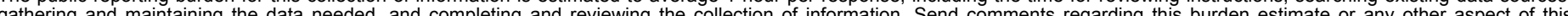

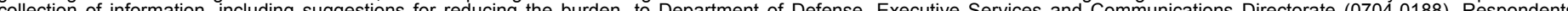

should be aware that notwithstanding any other provision of law, no person shall be subject to any penalty

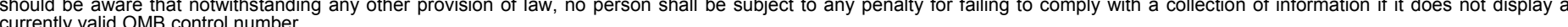

PLEASE DO NOT RETURN YOUR FORM TO THE ABOVE ORGANIZATION.

\begin{tabular}{l|l|l|l} 
1. REPORT DATE (DD-MM-YYYY) & 2. REPORT TYPE & 3. DATES COVERED (FrOm - TO)
\end{tabular}

March 2010

Conference Paper

4. TITLE AND SUBTITLE

Short Circuit Current Contribution for Different Wind Turbine

Generator Types: Preprint

5a. CONTRACT NUMBER

DE-AC36-08-GO28308

5b. GRANT NUMBER

5c. PROGRAM ELEMENT NUMBER

6. AUTHOR(S)

E. Muljadi, V. Gevorgian, N. Samaan, J. Li, and S. Pasupulati

5d. PROJECT NUMBER

NREL/CP-550-47193

5e. TASK NUMBER

WE10.4121

5f. WORK UNIT NUMBER
7. PERFORMING ORGANIZATION NAME(S) AND ADDRESS(ES)

National Renewable Energy Laboratory

1617 Cole Blvd.

Golden, CO 80401-3393

9. SPONSORING/MONITORING AGENCY NAME(S) AND ADDRESS(ES)

\section{PERFORMING ORGANIZATION REPORT NUMBER}

NREL/CP-550-47193
10. SPONSOR/MONITOR'S ACRONYM(S) NREL

11. SPONSORING/MONITORING AGENCY REPORT NUMBER

12. DISTRIBUTION AVAILABILITY STATEMENT

National Technical Information Service

U.S. Department of Commerce

5285 Port Royal Road

Springfield, VA 22161

13. SUPPLEMENTARY NOTES

14. ABSTRACT (Maximum 200 Words)

This paper presents simulation results for short-circuit current contribution for different types of WTGs obtained through transient analysis using generic WTG models.

\section{SUBJECT TERMS}

Fault contribution; grid integration; induction generator; protection; short circuit; wind power plant; wind turbine

\begin{tabular}{|c|c|c|}
\hline $\begin{array}{l}\text { a. REPORT } \\
\text { Unclassified }\end{array}$ & $\begin{array}{l}\text { b. ABSTRACT } \\
\text { Unclassified }\end{array}$ & $\begin{array}{l}\text { c. THIS PAGE } \\
\text { Unclassified }\end{array}$ \\
\hline
\end{tabular}

\begin{tabular}{l|l} 
17. LIMITATION & 18. \\
OF ABSTRACT & OF PAGES \\
UL &
\end{tabular}

19a. NAME OF RESPONSIBLE PERSON

19b. TELEPHONE NUMBER (Include area code) 